\title{
Serological evidence of infection with Chlamydia pneumoniae is related to the severity of asthma
}

\author{
P.N. Black*, R. Scicchitano**, C.R. Jenkins ${ }^{+}$, F. Blasi' ${ }^{++}$, L. Allegra ${ }^{++}$, J. Wlodarczyk ${ }^{\S}$, B.C. Cooper
}

Serological evidence of infection with Chlamydia pneumoniae is related to the severity of asthma. P.N. Black, R. Scicchitano, C.R. Jenkins, F. Blasi, L. Allegra, J. Wlodarczyk, B.C. Cooper. (C) ERS Journals Ltd 2000.

ABSTRACT: There is evidence that infection with Chlamydia pneumoniae is associated with asthma of recent onset and that it can influence the severity of asthma. This has led to the suggestion that macrolide antibiotics may be useful in the treatment of asthma in subjects infected with $C$. pneumoniae. This study examined the association between immunoglobulin (Ig)G and IgA titres to $C$. pneumoniae and the severity of asthma.

IgG and IgA antibodies to $C$. pneumoniae were measured in 619 subjects with asthma (18-60 yrs), using the microimmunofluoresence method. Subjects were asked about their use of asthma medicines, symptoms, previous hospitalization for asthma, smoking status and age of onset of asthma. In subjects with IgG titres of $\geq 1: 64$ and/or IgA titres $\geq 1: 16(n=212)$, spirometry was performed and peak expiratory flow rate (PEFR) and symptoms were recorded twice daily for 4 weeks on a diary card.

The use of high dose inhaled steroids was associated with an increase of $74.1 \%$ in the titre of IgG antibodies $(p=0.04)$ and an increase of $70.6 \%$ in the titre of $\operatorname{IgA}$ antibodies $(p=0.0001)$ when compared with the use of low dose inhaled steroids. There was an inverse association between IgG antibodies and forced expiratory volume in one second (FEV1) as a percentage of predicted in those subjects with elevated IgG and/or IgA $(p=0.04)$. In this group IgA antibodies were also associated with a higher daytime symptom score $(p=0.04)$.

Higher titres of antibodies to Chlamydia pneumoniae appears to be associated with markers of asthma severity. This raises the possibility that chronic infection with Chlamydia pneumoniae leads to an increase in the severity of asthma. Studies aimed at eradicating chronic infection with Chlamydia pneumoniae are necessary to determine whether or not this is the case.

Eur Respir J 2000; 15: 254-259.

Chlamydia pneumoniae, which was first described in 1986 [1], is an intracellular pathogen and is a common cause of respiratory tract infections [2]. It has been suggested that in New Zealand $46 \%$ of the adult population have immunoglobulin (Ig)G antibodies to C. pneumoniae $\geq 1$ :64 (Robert Scragg, Dept of Community Health, University of Auckland, personal communication) and that in Western Australia $57 \%$ of adults have titres $\geq 1: 32$ and $40 \%$ have titres $\geq 1: 128$ (Thomas Riley, Dept of Microbiology, University of Western Australia, personal communication).

There is evidence that infection with C. pneumoniae can influence the presentation of asthma. HAHN et al. [3] first noted an association between $C$. pneumoniae and asthma when they described four subjects who developed asthma following a lower respiratory tract infection due to $C$. pneumoniae. Four other individuals were reported to have an exacerbation of pre-existing asthma at the time that they were infected with C. pneumoniae [3]. HAHN et al. [4] went on to report a case control series demonstrating an association between adult onset asthma and IgA antibodies to $C$. pneumoniae (odds ratio $(\mathrm{OR})=3.7$ ). The relationship between asthma and infection with $C$. pneu-
*Dept of Medicine, University of Auckland, New Zealand; **Dept of Thoracic Medicine, Royal Adelaide Hospital, Adelaide, Australia; ${ }^{+}$Institute of Respiratory Medicine, Royal Prince Alfred Hospital, Sydney, Australia; ${ }^{++}$Institute of Respiratory Disease, University of Milan, IRCCS Ospedale Maggiore, Milano, Italy; ${ }^{\S} \mathrm{J}$ ohn Wlodarczyk Consulting Services, Newcastle, Australia; Hocchst Marion Roussel, Sydney, Australia.

Correspondence: P. Black, Dept of Medicine, Auckland Hospital, Private Bag 92024, Auckland, New Zealand. Fax: 64 93022101

\section{Keywords: Asthma}

Chlamydia pneumoniae

immunoglobulin A antibodies immunoglobulin $\mathrm{G}$ antibodies inhaled corticosteroids peak expiratory flow rate

Received: March 311999

Accepted after revision September 151999

The study was supported by Hoechst Marion Roussel. moniae was also studied by CUNNINGHAM et al. [5] in a cohort of children with asthma who were followed over the course of a year. Polymerase chain reaction (PCR) for $C$. pneumoniae was performed on nasopharyngeal aspirates from the children and secretory $\operatorname{IgA}$ antibodies to $C$. pneumoniae were measured in the same aspirates. Twenty-eight per cent of the children had a positive PCR for $C$. pneumoniae when they were well. The proportion of children with a positive PCR did not increase during exacerbations of their asthma but secretory $\operatorname{IgA}$ antibodies to $C$. pneumoniae were seven times higher in subjects who reported $\geq 4$ exacerbations during the study compared with those who reported only one exacerbation. CooK et al. [6] found that subjects with severe chronic asthma were significantly more likely to have IgG antibodies $\geq 1: 64$ or IgA antibodies $\geq 1: 8$ than subjects admitted to hospital with diseases other than asthma or chronic obstructive pulmonary disease (COPD).

In an uncontrolled study, HAHN [7] treated 46 subjects with adult onset asthma, who were seropositive for $C$. pneumoniae, with doxycycline, erythromycin or clarithromycin for 3-9 weeks. Half of these subjects had resolution of their asthma or a major improvement in their 
symptoms but this study can be criticized because of its open uncontrolled design. The authors are presently conducting a multicentre, randomized, double-blind, placebo controlled study of treatment with roxithromycin 150 b.i.d. for 6 weeks in subjects with asthma and high titres of $\operatorname{IgG}$ and/or IgA antibodies to $C$. pneumoniae. The authors have taken this opportunity to look for a relationship between titres for $C$. pneumoniae and the severity of asthma in the subjects screened for this study.

\section{Methods}

The $C$. pneumoniae, asthma, roxithromycin, multinational study (CARM) is a multicentre study conducted in Australia, New Zealand, Italy and Argentina. This report describes the 619 subjects screened in Australia and New Zealand. Permission to conduct the study was obtained from the Ethics Committee of each participating institution and all of the subjects gave written informed consent.

The majority of subjects were recruited after the study was publicized on television and in newspapers. Many of the centres conducted a prescreening process at the time of the initial telephone contact. In these centres, subjects who had few if any symptoms, were not invited to attend the study centre. A smaller proportion of the subjects were identified from hospital outpatient clinics.

Subjects were eligible for the study if they: were between the ages of 18-60 yrs; had a diagnosis of asthma; had a forced expiratory volume in one second (FEV1) between $50 \%$ and $90 \%$ of predicted; had $\geq 15 \%$ increase in FEV1 following inhaled salbutamol or $\geq 15 \%$ diurnal variation in peak expiratory flow rate (PEFR) on $7 / 14$ days during the run-in period; demonstrated IgG antibodies to C. pneumoniae $\geq 1: 64$ and/or IgA antibodies to $C$. pneumoniae $\geq 1: 16$; had a symptom score of $\geq 2$ (or night-time symptom score of $\geq 1$ ) on seven of the last 14 days of the run-in period.

All of the subjects who were screened for the study were between 18-60 yrs of age, had a physician diagnosis of asthma and were on treatment for asthma with $\geq 1$ inhaled medicines. At the initial screening visit blood was drawn for $C$. pneumoniae serology. Antibodies to C. pneumoniae were measured using the microimmunofluorescence technique (LabSystems, Helsinki, Finland). IgG antibodies were measured down to a titre of 1:64 and IgA antibodies down to a titre of 1:16 with lower titres being recorded as $\geq 1: 64$ and $<1: 16$ respectively. One laboratory measured all of the samples in Australia. A second laboratory measured the samples from the New Zealand centres.

The following information was also collected at the screening visit: age of onset of asthma; history of other atopic diseases i.e. allergic rhinitis or atopic eczema; smoking status; the dose of inhaled corticosteroid; asthma symptom score based on reported symptoms over the previous fortnight (table 1); the number of courses of prednisone or prednisolone in the previous year; the number of hospitalizations for asthma in the previous 5 yrs. In no instance had any of the subjects had antibodies to C. pneumoniae measured prior to the screening visit.

Subjects who had IgG titres to C. pneumoniae $\geq 1: 64$ or IgA titres $\geq 1: 16$ entered a run-in period. FEV1 and vital capacity (VC) and bronchodilator reversibility to inhaled salbutamol were measured at the beginning of the run-in
Table 1. - Asthma symptom score

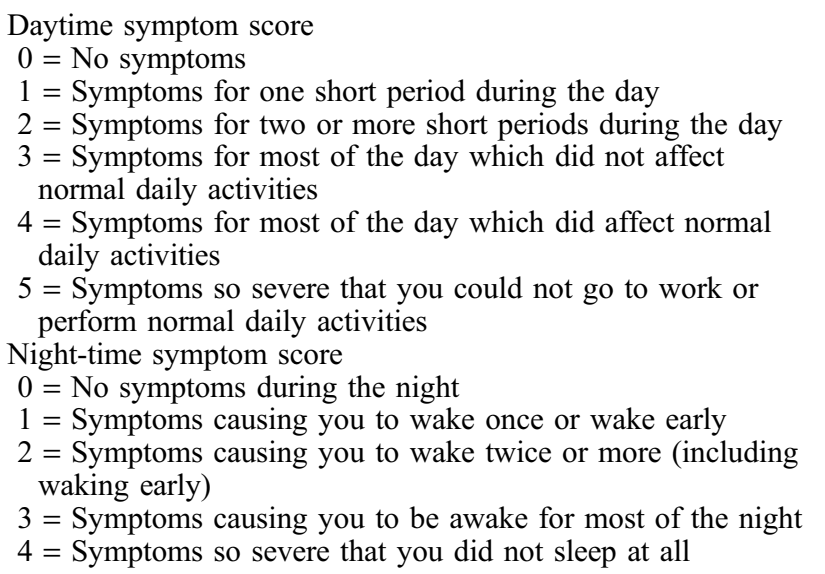

period. Subjects were then given a peak flow meter and diary card and were asked to record both their PEFR and their symptom score twice daily for 4 weeks (table 1). Subjects who met all of the eligibility criteria were then randomized to treatment with roxithromycin or placebo. Blood was also collected so that antibodies to adenovirus, influenza A and B, parainfluenza 1-3 and Mycoplasma pneumoniae could be assayed. Serology was performed at a central laboratory (Institute of Respiratory Diseases, Milan, Italy).

\section{Statistical analysis}

Information was collected on the following demographic variables: age, sex, smoking status, age at onset of asthma, history of atopy, significant respiratory tract infection in the previous 6 months and for the following measures of disease severity: hospitalization for asthma in the previous 5 yrs, the daytime and night-time symptom scores, FEV1, forced vital capacity (FVC) bronchodilator reversibility, morning and evening PEFR, diurnal variation in PEFR, use of inhaled bronchodilators and dose of inhaled corticosteroid. The dose of inhaled corticosteroid was classified as low $\left(<800 \mu \mathrm{g} \cdot \mathrm{day}^{-1}\right.$ of beclomethasone dipropionate or budesonide), medium $\left(\geq 800\right.$ and $<2000 \mu \mathrm{g} \cdot$ day $^{-1}$ of beclomethasone dipropionate or $<1600 \mu \mathrm{g} \cdot \mathrm{day}^{-1}$ of budesonide) or high $\left(>2,000 \mu \mathrm{g} \cdot \mathrm{day}^{-1}\right.$ of beclomethasone dipropionate, $\geq 1,600 \mu \mathrm{g} \cdot$ day $^{-1}$ of budesonide or $\geq 1,000$ $\mu \mathrm{g} \cdot \mathrm{day}^{-1}$ of fluticasone propionate). All of the subjects on treatment with budesonide used the Turbuhaler (Astra Pharmaceuticals, Sweden). There were no subjects on treatment with fluticasone propionate who used a dose of $<1,000 \mu \mathrm{g} \cdot \mathrm{day}^{-1}$.

Multivariate models were used to estimate the adjusted relationships between demographic/severity variables and titres of IgG and IgA antibodies to C. pneumoniae. IgA and IgG titres were approximately log normally distributed and were transformed accordingly. For the continuous analyses IgG titres $<1: 64$ were coded as $<1: 32$ and $\operatorname{IgA}$ titres $<1: 16$ were coded as 1:8. Linear regression models (SAS Proc Reg; SAS Institute Inc., Cary, NC, USA) were developed for the entire population of subjects screened for the study and for the subgroup who entered the run-in period and recorded their symptoms and PEFR each day for a fortnight (all of these subjects had IgG antibodies $\geq 1: 64$ and/or IgA antibodies $\geq 1: 16$ ). 
Logistic regression was used to build a nested case/ control model in which the cases were defined as having an IgA titre $\geq 1: 16$ together with an IgG titre $\geq 1: 64$ whereas control subjects had an IgA titre $<1: 16$ along with an IgG titre $<1: 64$. The subjects with IgG titres $\geq 1: 64$ and IgA titres $\geq 1: 16$ were analysed separately from the other subjects with IgG titres $\geq 1: 64$ because a previous study had found an association between IgA antibodies and adult onset asthma. In that study a similar association was not observed in the subjects who only had $\operatorname{IgG}$ antibodies to $C$. pneumoniae [4]. IgA and IgG antibody titres to C. pneumoniae were not available for six subjects. Twelve subjects had IgG titres $<1: 64$ but IgA titres $\geq 1: 16$.

Initially all variables described above were included as covariates, then a stepwise (backstepping) process was used to identify a reduced model which only used explanatory variables where $p<0.1$. Parameter estimates were similar for the full and reduced models. In this paper only the reduced models are presented.

Univariate analyses of the relationship between markers of severity and the dose of inhaled steroid were performed using Wilcoxon Rank Summary and Chi-squared tests, for continuous and categorical data as appropriate.

\section{Results}

The baseline characteristics of the subjects screened for the CARM study in Australia and New Zealand are shown in table 2. Of the 619 subjects screened for the study, $60.3 \%$ had $\mathrm{IgG}$ antibodies to C. pneumoniae $\geq 1.64$.

The logistic regression analysis compared the group with high titres of antibodies i.e. IgG antibodies $>1: 64$ and IgA antibodies $\geq 1: 16(n=212)$ to the group with IgG antibodies $<1: 64$ and IgA antibodies $<1: 16(n=210)$. Factors independently associated with the high titres of antibodies included age, male sex and smoking (table 3 ). In comparison with low dose inhaled steroids, high titres of antibody were associated with treatment with moderate dose inhaled steroids $(\mathrm{OR}=3.96,95 \%$ confidence interval $(\mathrm{CI})$ 2.09-7.52, $\mathrm{p}=0.0001)$, treatment with high dose inhaled steroids $(\mathrm{OR}=4.44,95 \%$ CI $2.30-8.56, \mathrm{p}=0.0001)$ and with not receiving inhaled steroids $(\mathrm{OR}=2.76,95 \% \mathrm{CI}$ 1.38-5.53, p=0.004) (table 3).

In the linear regression analysis the strongest associations with $\operatorname{IgA}$ antibodies were age (with an increase in antibody titre of $1.09 \%$ per year $(\mathrm{p}=0.008)$ ), smoking (with an increase in antibody titre of $1.64 \%$ for each pack year of smoking $(\mathrm{p}=0.04))$ and the use of high dose inhaled steroids (with a $70.60 \%$ increase in antibody titre compared with low dose inhaled steroids $(\mathrm{p}=0.0001)$ (table 4).

Table 2. - Baseline characteristics of the subjects with asthma screened for the Chlamydia pneumoniae, asthma, roxithromycin, multinational study (CARM) study

\begin{tabular}{lc}
\hline $\mathrm{n}$ & 619 \\
Age yrs & $41.5 \pm 12.1$ \\
Males \% & 45.2 \\
Current smokers \% & 5.5 \\
Exsmokers \% & 32.5 \\
Pack yrs $\#$ & $6.5 \pm 7.3$ \\
Age at onset of asthma yrs & $18.8 \pm 16.3$ \\
Atopy* \% & 77.7 \\
\hline
\end{tabular}

Data are presented as percentage or mean \pm SD. ${ }^{\#}$ : for current or exsmokers; *: on history (not skin testing).
Table 3. - Logistic regression comparing subjects with immunoglobulin (Ig) G antibodies $\geq 1: 64$ and IgA antibodies $\geq 1: 16 \quad(n=212)$ with subjects with IgG antibodies $<0: 64$ and $\lg A$ antibodies $<1: 16 \quad(n=210)$

\begin{tabular}{lccl}
\hline & Adjusted OR & $95 \%$ CI & p-value \\
\hline Age per year & 1.02 & $1.00-1.04$ & 0.09 \\
$\begin{array}{l}\text { Smoking pack yrs } \\
\begin{array}{l}\text { Not on inhaled } \\
\text { steroids* }\end{array}\end{array}$ & 1.08 & $1.03-1.14$ & 0.002 \\
$\begin{array}{l}\text { Moderate dose inhaled } \\
\text { steroids* }\end{array}$ & 3.96 & $1.38-5.53$ & 0.004 \\
$\begin{array}{l}\text { High dose inhaled } \\
\text { steroids* }\end{array}$ & 4.44 & $2.09-7.52$ & 0.0001 \\
\hline
\end{tabular}

*: compared with treatment with low dose inhaled steroids. OR: odds ratio; CI: confidence intervals.

With IgG antibodies the strongest associations were age (with an increase in antibody titre of $1.54 \%$ per year $(0.0002)$ ), smoking (with an increase in antibody titre of $2.09 \%$ for each pack year $(\mathrm{p}=0.009)$ ), male sex (with an increase in titre of $31.5 \%(\mathrm{p}=0.03)$ and the use of high dose inhaled steroids (with an increase in titre of $74.07 \%$ compared with low dose-inhaled steroids $(\mathrm{p}=0.04)$ (table 5)).

Figure 1 shows that the lowest geometric mean titres for IgG and IgA antibodies to C. pneumoniae are seen in the low dose inhaled steroid group. Markers of severity are presented according to the dose of inhaled steroid in table 6 . Subjects who were not on treatment with inhaled steroids had higher symptom scores than subjects on low dose inhaled steroids.

The results of diary card data and of spirometry were available for 135 subjects. The markers or severity included in this multivariate analysis were the mean morning and evening PEFR, mean day- and night-time symptom scores, FEV1 as a percentage of predicted, dose of inhaled steroid (none, low, medium or high dose), ever treated with oral corticosteroids, and hospitalization for asthma in the previous 5 yrs. When these data were analysed the variables independently associated with $\operatorname{IgA}$ titres to $C$. pneumoniae were the use of high dose inhaled steroids $(\mathrm{p}=$ $0.002)$, the mean daytime symptom score $(\mathrm{p}=0.04)$ and FEV1 as a percentage of predicted $(\mathrm{p}=0.1)$. There was an increase in titre of $25.3 \%$ for each point on the daytime symptom score $(\mathrm{p}=0.04)$. The only variable associated with

Table 4. - Linear regression of variables associated with immunoglobulin A antibody titres to Chlamydia pneumoniae

\begin{tabular}{lccl}
\hline & $\begin{array}{c}\text { Percentage } \\
\text { change } \\
\text { in titre }\end{array}$ & $\begin{array}{c}95 \% \\
\text { confidence } \\
\text { intervals }\end{array}$ & p-value \\
\hline Age yrs & 1.1 & $0.3-1.9$ & 0.008 \\
$\begin{array}{l}\text { Smoking pack yrs* } \\
\begin{array}{c}\text { Not on inhaled } \\
\text { steroids }\end{array}\end{array}$ & 1.6 & $0.1-3.2$ & 0.04 \\
$\begin{array}{c}\text { Moderate dose inhaled } \\
\text { steroids }\end{array}$ & 65.6 & $9.7-93.3$ & 0.01 \\
$\begin{array}{l}\text { High dose inhaled } \\
\text { steroids }\end{array}$ & 70.6 & $24.6-108.0$ & 0.0003 \\
\hline
\end{tabular}

${ }^{\#}$ : increase in titre for each year of age; $*$ : increase in titre for each pack year of smoking; ${ }^{*}$ : compared to treatment with low dose inhaled steroids. 
Table 5. - Linear regression of variables associated with immunoglobulin $\mathrm{G}$ antibody titres to Chlamydia pneumoniae

\begin{tabular}{lccl}
\hline & $\begin{array}{c}\text { Percentage } \\
\text { change } \\
\text { in titre }\end{array}$ & $\begin{array}{c}95 \% \\
\text { confidence } \\
\text { intervals }\end{array}$ & p-value \\
\hline Age yrs* & 1.5 & $0.6-2.5$ & 0.0002 \\
Smoking pack yrs & 2.1 & $0.3-3.9$ & 0.009 \\
Male sex & 31.5 & $6.0-63.0$ & 0.03 \\
$\begin{array}{l}\text { Not on inhaled } \\
\text { steroids }\end{array}$ & 42.1 & $2.6-96.8$ & 0.04 \\
Moderate dose inhaled $_{\text {steroids }}^{+}$ & 61.1 & $20.0-116.3$ & 0.02 \\
High dose inhaled $^{+}$ & 74.1 & $28.5-135.8$ & 0.04 \\
steroids $^{+}$ & & & \\
\hline
\end{tabular}

*: increase in titre for each year of age; ${ }^{*}$ : increase in titre for each pack year of smoking; ${ }^{*}$ : compared to females; ${ }^{+}$: compared to treatment with low dose inhaled steroids.

the titre of $\operatorname{IgG}$ antibodies was FEV1 as a percentage of predicted $(\mathrm{p}=0.04)$. The titre of antibody increased by $0.8 \%$ for every $1 \%$ decrease in the FEV 1 as percentage of predicted. No relationship was seen between the severity of asthma and the antibody titres to $M$. pneumoniae, adenovirus, influenza A and B or parainfluenza 1-3 (data not shown).

\section{Discussion}

This study provided evidence of an association between markers of the severity of asthma and the geometric mean titre of antibody to $C$. pneumoniae. This was most clearly seen with the higher titres of antibodies to $C$. pneumoniae in the subjects on treatment with high dose inhaled corticosteroids. When subjects with the combination of IgG titres $\geq 1: 64$ and IgA titres $\geq 1: 16$ were compared in the logistic regression analysis with those with $\operatorname{IgG}$ titres $<1: 64$, the OR for the use of high dose inhaled corticosteroids (as opposed to use of low dose inhaled corticosteroids) was 4.44 (95\% CI 2.30-8.56) ( $\mathrm{p}=0.0001)$.

In the subset of patients for whom FEV1 and prospective symptom scores were available, IgA titres to C. pneumoniae were independently associated with the daytime symptom score as well as the dose of inhaled steroid and were inversely associated with FEV1 (\% predicted) while the IgG titres were inversely associated with FEV1 (\% pred).

In this study, the geometric mean titre of IgG antibodies to $C$. pneumoniae was higher in males and in smokers. This is consistent with studies in the general population where both the prevalence and the geometric mean titre of antibodies to $C$. pneumoniae were increased in these

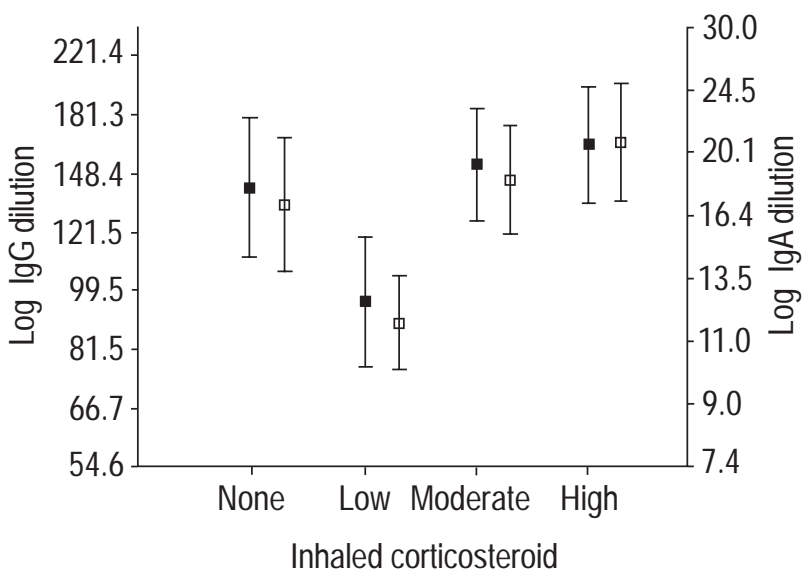

Fig. 1. - Geometric mean titres (95\% confidence intervals) of Chlamydia pneumoniae antibody versus the dose of inhaled steroid. The four groups for the dose of inhaled steroid (none, low, moderate and high) are defined in the section on statistical analysis. $\square$ : immunoglobulin (Ig)G titres; $\square$ : IgA titres.

groups [2]. In this study, $60.3 \%$ of the subjects had IgG antibody titres to $C$. pneumoniae of $\geq 1: 64$. In New Zealand a survey of individuals between the ages of 35-64 yrs who were randomly selected from the electoral role found that the prevalence of $\mathrm{IgG}$ antibodies $\geq 1: 64$ was 43\% (Robert Scragg, Dept of Community Health, University of Auckland, personal communication). Although the current findings suggest that the prevalence of antibodies to $C$. pneumoniae is increased in subjects with asthma it is important to note that there was not a control group. Nor are the subjects representative of all subjects with asthma. Further studies need to be conducted to determine whether the prevalence of antibodies to $C$. pneumoniae is increased in asthma.

The findings suggest that infection with $C$. pneumoniae might lead to an increase in the severity of asthma but the study has not proven this beyond doubt. A particularly strong association was found between the use of high dose inhaled steroids $\left(\geq 2,000 \mu \mathrm{g} \cdot\right.$ day $^{-1}$ of beclomethasone dipropionate or equivalent) and the titre of antibodies to $C$. pneumoniae. The possibility that the use of high dose inhaled steroids predisposes to infection with $C$ pneumoniae cannot be excluded. In a mouse model treatment with cortisone led to reactivation of infection with $C$. pneumoniae $[8,9]$. Against this is the observation that other markers of severity including FEV1 and symptom scores were independently associated with severity in the multivariate analysis.

The higher titres of antibodies to $C$. pneumoniae in the patients with more severe asthma could also represent an anamnestic response but this is unlikely to be the case

Table 6. - Relationship between dose of inhaled steroid and markers of severity

\begin{tabular}{lcccc}
\hline & $\begin{array}{c}\text { Not on inhaled } \\
\text { steroids }\end{array}$ & $\begin{array}{c}\text { Low dose } \\
\text { inhaled steroids }\end{array}$ & $\begin{array}{c}\text { Moderate dose } \\
\text { inhaled steroids }\end{array}$ & $\begin{array}{c}\text { High dose } \\
\text { inhaled steroids }\end{array}$ \\
\hline $\mathrm{n}$ & 130 & 128 & 181 & 170 \\
Daytime symptom score & $1.89 \pm 0.93$ & $1.74 \pm 0.96$ & $1.89 \pm 0.98$ & $2.21 \pm 0.98$ \\
Night-time symptom score & $0.86 \pm 0.77$ & $0.79 \pm 0.77$ & $0.77 \pm 0.69$ & $0.89 \pm 0.95$ \\
Hospitalized in last 5 yrs \% & 10.0 & 9.4 & 14.4 & $0.78^{*}$ \\
\hline
\end{tabular}

Results are expressed as mean \pm SD or as a percentage. *: Wilcoxon rank sum test; ${ }^{+}$: Chi-squared test. 
because no relationship was seen between the severity of asthma and antibody titres to $M$. pneumoniae, adenovirus, influenza A or B, or parainfluenza [1-3].

It may appear surprising that the subjects who were not using inhaled steroids had higher titres of antibodies to $C$. pneumoniae than the subjects on low dose inhaled corticosteroids but it should be noted that the subjects who were not using inhaled steroids had higher symptom scores than those on low dose inhaled steroids. It cannot be assumed that the subjects who were not using inhaled steroids had mild asthma. Indeed during the screening process the authors identified subjects with severe asthma who had been prescribed inhaled steroids but who for a variety of reasons had opted not to take them. The higher levels of antibodies in the subjects who were not using inhaled corticosteroids is another reason for believing that the findings are not simply due to reactivation of infection of $C$. pneumoniae with the use of high dose inhaled corticosteroids.

The association between the titre of antibody and the severity of disease is not limited to asthma. Similar associations have been reported for coronary artery disease. THом et al. [10] studied 461 subjects who had $\geq 1$ lesions demonstrated on coronary angiography. Severe coronary artery disease was defined as $\geq 5$ lesions. Subjects with IgG titres to $C$. pneumoniae of $\geq 1: 64$ had a 2.8 -fold increased risk of severe coronary disease compared with those with titres of $\leq 1: 8$. In another study of subjects with unstable angina, those with $\operatorname{IgA}$ titres $\geq 1: 64$ had higher levels of fibrinogen than the other subjects [11].

There is increasing evidence that chronic infection with C. pneumoniae occurs in man. Several studies have demonstrated $C$. pneumoniae in atherosclerotic plaques using immunohistochemistry and PCR $[12,13]$ and recently $C$. pneumoniae has been cultured from a coronary artery [14]. VON HERTZEN et al. [15] studied subjects with severe COPD when they were admitted to hospital or when they presented to the outpatient clinic. Twenty-three of the 39 subjects $(59 \%)$ were positive for $C$. pneumoniae when PCR was performed on sputum and 28/35 (80\%) had secretory $\operatorname{IgA}$ antibodies to $C$. pneumoniae in the sputum but none had serological evidence of acute infection. This suggests that the changes in the sputum represent chronic infection. If chronic infection with $C$. pneumoniae occurs in patients with atherosclerosis and COPD it is reasonable to speculate that many subjects with asthma could also have chronic infection with $C$. pneumoniae. The study by Cunningham et al. [5] where the PCR for C. pneumoniae was positive in a quarter of the children with asthma even when they were well, is consistent with this idea.

In this study the authors did not try to detect $C$. pneumoniae in the airways using PCR or immunohistochemistry so this study does not provide direct evidence that higher titres of antibody represent a greater degree of infection with $C$. pneumoniae but such an association has been demonstrated in other studies. Using immuno-histochemistry and PCR, DAVIDSON et al. [16] detected C. pneumoniae in the coronary arteries of $37 \%$ of a group of Alaskan natives. The subjects, who died at a mean age of $34.1 \mathrm{yrs}$, had evidence of the early lesions of atherosclerosis. Antibodies to C. pneumoniae were measured in serum which had been collected several years before death. The likelihood of detecting $C$. pneumoniae with immunohistochemistry or PCR increased with the titre of
IgG antibodies. With IgG antibodies of $\geq 1: 256$, the adjusted OR for the detection of C. pneumoniae was 9.40.

The question arises of how chronic infection with $C$. pneumoniae might lead to an increase in the severity of asthma. There is increased production of cytokines including interleukin (IL)-1, tumour necrosis factor (TNF)- $\alpha$ and IL-6 in monocytes infected with $C$. pneumoniae [17] and increased formation of IL-1, regulated on activation, normal T-cell expressed and secreted (RANTES), IL-16 and granulocyte macrophage-colony stimulating factor (GMCSF) has been demonstrated in bronchial epithelial cells infected with $C$. pneumoniae [18]. Increased formation of pro-inflammatory cytokines such as TNF- $\alpha$, RANTES or GM-CSF could influence the severity of asthma.

If infection with Chlamydia pneumoniae does increase the severity of asthma treatment with antibiotics to eradicate this organism could lead to an improvement in asthma control although it can be difficult to eradicate intracellular pathogens such as Chlamydia pneumoniae [19]. The results of the current study and others which address this question are awaited.

Acknowledgements. S. Hopkins, H. Ormandy, S. Culhane, J. Flynn, C. Ryan (Hoechst Marion Roussel) are thanked for performing the study co-ordination and monitoring. The following centres and investigators took part in the study in Australia and New Zealand: Australia: Concord Repatriation Hospital, Sydney (M. Peters); Flinders Medical Centre, Adelaide (J. Alpers); Fremantle Hospital, Fremantle (P. Bremner); John Hunter Hospital, Newcastle (P. Gibson); Mater Medical Centre, Brisbane (S. Bowler); Princess Alexandra Hospital, Brisbane (C. Mitchell); Queen Elizabeth Hospital, Adelaide (R. Ruffin); Royal Adelaide Hospital, Adelaide (R. Scicchitano); Royal Melbourne Hospital, Melbourne; (A. Rubinfeld); Royal Prince Alfred Hospital, Sydney (C. Jenkins); Sir Charles Gairdner Hospital, Perth (M. Phillips); St. Vincent's Hospital, Melbourne (J. Burdon); Westmead Hospital, Sydney (C. Katelaris). New Zealand: Auckland Hospital, Auckland (P. Black); Christchurch Hospital, Christchurch (I. Town); Waikato Hospital, Hamilton (G. Mills).

\section{References}

1. Grayston JT, Kuo C, Wang ST, Altman J. A new Chlamydia psittaci strain, TWAR, isolated in acute respiratory tract infections. $N$ Engl J Med 1986; 315: 161-168.

2. Grayston JT, Campbell LA, Kuo CC, et al. A new respiratory tract pathogen Chlamydia pneumoniae strain TWAR. J Infect Dis 1990; 161: 618-625.

3. Hahn DL, Dodge R, Golubjatnikov R. Association of Chlamydia pneumoniae (strain TWAR) infection with wheezing, asthmatic bronchitis and adult onset asthma. JAMA 1991; 266: 225-230.

4. Hahn DL, Anttila T, Saikku P. Association of Chlamydia pneumoniae IgA antibodies with recently symptomatic asthma. Epidemiol Infect 1996; 117: 513-517.

5. Cunningham AF, Johnston SL, Julious SA, Lampe FC, Ward ME. Chronic Chlamydia pneumoniae and asthma exacerbations in children. Eur Respir J 1998; 11: 345349.

6. Cook PJ, Davies P, Tunnicliffe W, Ayres JG, Honeybourne D, Wise R. Chlamydia pneumoniae and asthma. Thorax 1998; 53: 254-259. 
7. Hahn DL. Treatment of Chlamydia pneumoniae infection in adult asthma in adult asthma: a before-after trial. J Fam Pract 1995; 41: 345-351.

8. Malinveri R, Kuo C-C, Campbell LA, Grayston JT. Reactivation of Chlamydia pneumoniae lung infection in mice by cortisone. J Infect Dis 1995; 172: 593-594.

9. Laitinen K, Laurila AL, Leinonen M, Saikku P. Reactivation of Chlamydia pneumoniae infection in mice by cortisone treatment. Infect Immunity 1996; 64: 14881490.

10. Thom DH, Wang S-P, Grayston JT, et al. Chlamydia pneumoniae strain TWAR antibody and angiographically demonstrated coronary disease. Arterioscler Thromb 1991; 11: 547-551.

11. Toss H, Gnarpe J, Gnarpe H, Siegbahn A, Lindahl B, Wallentin L. Increased fibrinogen levels are associated with persistent Chlamydia pneumoniae infection in unstable coronary disease. Eur Heart J 1998; 19: 570577.

12. Kuo CC, Shor A, Campbell LA, Fukushi H, Patton DL, Grayston JT. Demonstration of Chlamydia pneumoniae in atherosclerotic lesions of coronary arteries. $J$ Infect Dis 1993; 167: 841-849.

13. Muhlestein JB, Hammond EH, Carlquist JF, et al. Increased incidence of chlamydia species within the coronary arteries of patients with symptomatic atherosclerosis versus other forms of cardiovascular disease. $J$ Am Coll Cardiol 1996; 27: 1555-1561.

14. Ramirez JA and Chlamydia pneumoniae/Atherosclerosis Study Group. Isolation of Chlamydia pneumoniae from the coronary artery of a patient with coronary atherosclerosis. Ann Intern Med 1996; 125: 979-982.

15. Von Hertzen L, Alarkärppä H, Koskinen R, et al. Chlamydia pneumoniae infection in patients with chronic obstructive pulmonary disease. Epidemiol Infect 1997; 118: 155-164.

16. Davidson M, Cho-Chou K, Middaugh JP, et al. Confirmed previous infection with Chlamydia pneumoniae (TWAR) and its presence in early coronary atherosclerosis. Circulation 1998; 98: 628-633.

17. Heinemann M, Susa M, Simnacher U, Marre R, Essig A. Growth of Chlamydia pneumoniae induces cytokine production and expression of CD14 in a human monocytic cell line. Infect Immun 1996; 64: 4872-4875.

18. Biscione G, Hussain IR, Papi A, Johnston SL. Pathophysiology of Chlamydia pneumoniae infections. Proc $4 \mathrm{~h}$ International Conference on Macrolides, Streptogammins \& Ketolides, 1998; p. 44.

19. Hammerschlag MR, Chirgwink K, Roblin PM, et al. Persistent infection with Chlamydia pneumoniae following acute respiratory illness. Clin Infect Dis 1992; 14: $178-182$. 